\title{
Muscles and lungs: fatal attraction, but time for intervention
}

\author{
J.C. Winck, M. Gonçalves
}

Monaldi Arch Chest Dis 2005; 63: 3, 121-123.

Lung Function and Rehabilitation Unit, Pulmonology Service, Faculdade de Medicina do Porto, Portugal.

Correspondence: Prof João Carlos Winck, Serviço de Pneumologia, Faculdade de Medicina, Hospital São João, $4202-451$ Porto-Portugal, jwinck@hsjoao.min-saude.pt

The act of breathing entails the integrity and function of the respiratory muscles [1]; however, diseases of the lung can also influence the muscle pump.

It is well known that neuromuscular damage have a strong impact on respiration [2] and that hyperinflation that accompanies COPD interferes with respiratory muscle function [3]. More recent evidence suggests that even respiratory tract infections can lead directly to muscle weakness [4]. Animal models imply that sepsis is associated with respiratory muscles dysfunction mediated through oxygen-derived free radicals [5]. Moreover controlled mechanical ventilation has been shown to induce diaphragmatic dysfunction [6] creating the possibility of a deleterious additive and/or synergistic with infection [7].

So an examination of the relationship between the Muscle Pump and the Lung can be useful for the clinician.

Although patients with pre-existing Neuromuscular Disease (NMD) are not commonly seen in the ICU [8] and seldom included in randomised controlled trials of Non Invasive Ventilation (NIV) [9], acquired NMD seems very common yet unrecognised $[10,11]$. Respiratory failure due to these disorders needs a different approach from the more common obstructive pulmonary diseases [12, 13]. They need a special focus since well established therapeutical protocols may improve the outcomes $[14,15]$ and may reduce weaning time [16].

\section{Acute Respiratory Failure (ARF) in patients with pre-existing NMD}

In Respiratory Intensive Care Units (RICU), ARF due to NMD account for $4-12.5 \%$ of cases $[17,18]$ rising to $25 \%$ in weaning centres [19].

In patients with NMD, the development of upper respiratory tract infections significantly reduce respiratory muscle strength (with a mean fall of $12 \mathrm{~cm} \mathrm{H}_{2} \mathrm{O}$ in maximal inspiratory pressure-MIPand $10 \mathrm{cmH}_{2} \mathrm{O}$ of maximal expiratory pressureMEP), probably by direct muscle injury [20]. Hypoventilation and hypercapnia ensues and cough efficacy becomes seriously compromised. In this setting, if emphasis is only on improving ventilation, the outcomes will be poor [21]. The use of non invasive mechanical aids to clear bronchial secretions should be added to improve clinical outcomes and avoid intubation or tracheostomy ventilation [14, 22-26]. During weaning, combination a of NIV and mechanical in-exsufflation should also be applied $[15,16]$.

\section{Acquired NMD in the Intensive Care Unit (ICU)}

From multicentre prospective studies it is estimated that $25.3 \%$ of patients who underwent mechanical ventilation (MV) for more than 7 days, develop Acquired NMD [10]. Corticosteroid administration is strongly associated with the occurrence of Acquired NMD [10], but neuromuscular blocking agents, aminoglycosides, hyperglycemia and sepsis are also risk factors [11]. Monitoring of respiratory muscle strength should be commonly performed in the ICU [2] and avoiding re-exposure to drugs, strict control of blood glucose levels and infection should be promptly implemented.

It has been shown that ICU-acquired NMD contributes to prolonged $\mathrm{MV}$ in critically ill patients [27], so early identification of the disease can have an impact on prognosis. Cough inefficacy and reduction in maximal respiratory pressures have also been reported in these patients [28], suggesting the implementation of secretion clearance techniques together with ventilatory support.

In this issue of the Journal, Vitacca et al [29] show that one third of patients admitted to an RICU, with severe exacerbation of COPD have a reduction in respiratory muscle strength.

The authors describe their experience with the evaluation of lung and respiratory function at RICU discharge of patients with a severe COPD exacerbation. In their Unit, with a high percentage of COPD admissions ( $75 \%$ of all cases) over one year, these investigators prospectively described a cohort of 42 patients with a severe exacerbation. They showed that at discharge, $33 \%$ of cases had significant deterioration of MIP compared with 
stable state values. The majority of patients (55\%) had required prolonged weaning and ventilation through a tracheotomy. Among patients with tracheotomy, mean RICU stay was $17 \pm 5$ days, decannulation was possible in only $13 \%$ and respiratory muscle decrease was not significantly different from non-tracheotomised patients. Vitacca et $a l$ also demonstrated that no parameter assessed in stable state could predict lung and respiratory muscle function worsening during exacerbation.

As suggested above, the authors should have mentioned total doses of corticosteroids and neuromuscular blocking agents used before admission into the RICU, as they predominately studied patients from ICU. Although the aetiology of muscle weakness in COPD seems multi-factorial $[3,11]$, drug-induced neuromuscular damage could also be involved. Moreover, respiratory muscle deterioration in these subset of patients, could also be attributed to failure to significantly decrease lung hyperinflation [30] or ventilator-induced diaphragmatic dysfunction [6] since $55 \%$ of cases had long ICU stay (from 10 to 45 days).

This study clearly outlines the importance of evaluating respiratory muscle strength in critically ill patients, a subject that is still under investigated.

According with the work of Vitacca et al [29] and previous studies [28], monitoring of respiratory muscles is highly recommended after discharge from RICU in patients in whom neuromuscular damage is identified. This can lead to implementation of early muscle retraining and respiratory rehabilitation. In fact, Weiner et al [31], in a small randomized controlled trial, demonstrated that corticosteroid induced muscle weakness was preventable by inspiratory muscle training (IMT) using the Threshold ${ }^{\circledR}$ trainer. From a meta-analysis, it has been suggested that IMT has a role in COPD patients with inspiratory muscle weakness [32].

The results of Vitacca et al are of clinical importance because they raise new questions with respect to the management of COPD: Which patients with acute exacerbations of COPD have clinically significant respiratory muscle weakness? What are the main causes and how should we prevent and treat them? Will the length of the hospital stay increase for patients with more severe muscle function impairment?

Although acquired-NMD was first described in patients with severe acute asthma [33], recent studies also suggest a high prevalence (34.6\%) in patients intubated due to exacerbation of COPD [34]. In these patients, total doses of corticosteroids, APACHE score at admission and occurrence of sepsis were considered risk factors for acquired-NMD [34]. Systemic Corticosteroids (specially given in repetitive bursts) have been also directly implicated in the reduction of MIP and MEP in spontaneous breathing COPD patients with an acute exacerbation [35].

Moreover, acute exacerbations per se, can decrease peripheral muscle force in COPD patients, related to the production of inflammatory markers like IL-8 and IGF-I [36]. In animal models there is also strong evidence suggesting that TNF- $\alpha$, a common systemic mediator in COPD, can compromise respiratory muscle function [37].

Where do we go from here? We need to know whether there are specific interventions in this setting...

\section{Treatment of Acquired-NMD in the ICU}

Unfortunately there is no specific treatment for Acquired-NMD, although different trials have tested recombinant Growth Hormone [38] in this setting. In COPD, this intervention didn't achieve any significant results [39]. However intensive Insulin therapy does seem to reduce significantly the incidence of Acquired NMD [40].

So, efforts should be made to search for new treatments like agents that inhibit free-radical synthesis, which may be of benefit in preventing the development of respiratory muscle dysfunction and respiratory failure in selected patients with infections [5]. Until then, prevention should be our first goal as much of this acquired-NMD is drugrelated. Moreover, to avoid ventilator-induced diaphragmatic dysfunction we should restrain the use of Controlled Mechanical Ventilation to the minimum possible.

Moreover, as Vitacca et al suggested, there is growing evidence which is supported by a recent meta-analysis, that Respiratory Rehabilitation initiated immediately after acute exacerbations of COPD reduces the risk for hospital admission and mortality [41].

Further studies are needed to confirm these findings, exploring this expanding field of respiratory failure and neuromuscular damage.

\section{References}

1. Laghi F, Tobin MJ. Disorders of the respiratory muscles. Am J Respir Crit Care Med 2003; 168: 10-48.

2. Polkey MI, Moxham J. Clinical aspects of respiratory muscle dysfunction in the critically ill. Chest 2001; 119: 926-939.

3. Cassart M, Pettiaux N, Gevenois PA, et al. Effect of chronic hyperinflation on diaphragm length and surface area. Am J Respir Crit Care Med 1997; 156: 504-508.

4. Divangahi M, Matecki S, Dudley RWR, et al. Preferential Diaphragmatic Weakness during Sustained Pseudomonas aeruginosa Lung Infection. Am J Respir Crit Care Med 2004; 169: 679 - 686.

5. Callahan LA, Nethery D, Stofan D, et al. Free radicalinduced contractile protein dysfunction in endotoxininduced sepsis. Am J Respir Cell Mol Biol 2001; 24: 210-217.

6. Vassilakopoulos T, Petrof BJ. Ventilator-induced diaphragmatic dysfunction. Am J Respir Crit Care Med 2004; 169: 336-341.

7. Boczkowski J. Lung infection and the diaphragm: placing basic research in clinical perspective. Am J Respir Crit Care Med 2004; 169: 662-663.

8. Esteban A, Anzueto A, Frutos F, et al. Characteristics and outcomes in adult patients receiving mechanical ventilation: a 28-day international study. JAMA 2002; 287: 345-355.

9. Martin TJ, Hovis JD, Costantino JP, et al. A randomized, prospective evaluation of noninvasive ventilation for acute respiratory failure. Am J Respir Crit Care Med 2000; 161: 807-813. 
10. De Jonghe B, Sharshar T, Lefaucheur JP, et al. Paresis acquired in the intensive care unit: a prospective multicenter study. JAMA 2002; 288: 2859-2867.

11. Deem S, Lee CM, Curtis JR. Acquired neuromuscular disorders in the intensive care unit. Am J Respir Crit Care Med 2003; 168: 735-739.

12. Tzeng AC, Bach JR. Prevention of pulmonary morbidity for patients with neuromuscular disease. Chest 2000; 118: 1390-1396.

13. Robino C, Faisy C, Diehl JL, et al. Effectiveness of non-invasive positive pressure ventilation differs between decompensated chronic restrictive and obstructive pulmonary disease patients. Intensive Care Med 2003; 29: 603-610.

14. Vianello A, Corrado A, Arcaro G, et al. Mechanical insufflation-exsufflation improves outcomes for neuromuscular disease patients with respiratory tract infections. Am J Phys Med Rehabil 2005; 84: 83-88.

15. Simonds AK. Streamlining weaning: protocols and weaning units. Thorax 2005; 60: 175-182.

16. Bach JR, Goncalves M. Ventilator weaning by lung expansion and decannulation. Am J Phys Med Rehabil 2004; 83: 560-568.

17. Confalonieri M, Gorini M, Ambrosino N, et al. Respiratory intensive care units in Italy: a national census and prospective cohort study. Thorax 2001; 56: 373-378.

18. Ceriana P, Delmastro M, Rampulla C, et al. Demographics and clinical outcomes of patients admitted to a respiratory intensive care unit located in a rehabilitation center. Respir Care 2003; 48: 670-676.

19. Pilcher DV, Bailey MJ, Treacher DF, et al. Outcomes, cost and long term survival of patients referred to a regional weaning centre. Thorax 2005; 60: 187-192.

20. Poponick JM, Jacobs I, Supinski G, et al. Effect of upper respiratory tract infection in patients with neuromuscular disease. Am J Respir Crit Care Med 1997; 156: 659-664.

21. Bradley MD, Orrell RW, Clarke J, et al. Outcome of ventilatory support for acute respiratory failure in motor neurone disease. J Neurol Neurosurg Psychiatry 2002; 72: 752-756.

22. Bach JR. Mechanical insufflation-exsufflation: comparison of peak expiratory flows with manually assisted and unassisted coughing techniques. Chest 1993; 104: 1553-1562.

23. Bach JR. Update and perspective on noninvasive respiratory muscle aids. Part 2: The expiratory aids. Chest 1994; 105: 1538-1544.

24. Winck JC, Goncalves MR, Lourenco C, et al. Effects of mechanical insufflation-exsufflation on respiratory parameters for patients with chronic airway secretion encumbrance. Chest 2004; 126: 774-780.

25. Hanayama K, Ishikawa Y, Bach JR. Amyotrophic lateral sclerosis. Successful treatment of mucous plugging by mechanical insufflation-exsufflation. Am J Phys Med Rehabil 1997; 76: 338-339.

26. Servera E, Sancho J, Gomez-Merino E, et al. Non-invasive management of an acute chest infection for a patient with ALS. J Neurol Sci 2003; 209: 111-113.
27. De Jonghe B, Bastuji-Garin S, Sharshar T, et al. Does ICU-acquired paresis lengthen weaning from mechanical ventilation? Intensive Care Med 2004; 30: 11171121.

28. Latronico N, Guarneri B, Alongi S, et al. Acute neuromuscular respiratory failure after ICU discharge. Report of five patients. Intensive Care Med 1999; 25: 1302-1306.

29. Vitacca M, Bianchi L, Barbano L, et al. Lung and respiratory muscle function at discharge from a respiratory intensive care unit. Monaldi Arch Chest Dis 2005; 3: 142-148.

30. Gonzalez C, Servera E, Celli B, et al. A simple noninvasive pressure-time index at the mouth to measure respiratory load during acute exacerbation of COPD A comparison with normal volunteers. Respir Med 2003; 97: 415-420.

31. Weiner P, Azgad Y, Weiner M. Inspiratory muscle training during treatment with corticosteroids in humans. Chest 1995; 107: 1041-1044.

32. Lotters F, van Tol B, Kwakkel G, et al. Effects of controlled inspiratory muscle training in patients with COPD: a meta-analysis. Eur Respir J 2002; 20: 570-576.

33. Leatherman JW, Fluegel WL, David WS, et al. Muscle weakness in mechanically ventilated patients with severe asthma. Am J Respir Crit Care Med 1996; 53: 1686-1690.

34. Amaya-Villar R, Garnacho-Montero J, Garcia-Garmendia JL, et al. Steroid-induced myopathy in patients intubated due to exacerbation of chronic obstructive pulmonary disease. Intensive Care Med 2005; 31: 157-161.

35. Decramer M, Lacquet LM, Fagard R, et al. Corticosteroids contribute to muscle weakness in chronic airflow obstruction. Am J Respir Crit Care Med 1994; 150: 11-16.

36. Spruit MA, Gosselink R, Troosters T, et al. Muscle force during an acute exacerbation in hospitalised patients with COPD and its relationship with CXCL8 and IGF-I. Thorax 2003; 58: 752-756.

37. Reid MB, Lannergren J, Westerblad H. Respiratory and limb muscle weakness induced by tumor necrosis factor-alpha: involvement of muscle myofilaments. Am J Respir Crit Care Med 2002; 166: 479-484.

38. Pichard C, Kyle U, Chevrolet JC, et al. Lack of effects of recombinant growth hormone on muscle function in patients requiring prolonged mechanical ventilation: a prospective, randomized, controlled study. Crit Care Med 1996; 24: 403-413.

39. Burdet L, de Muralt B, Schutz Y, et al. Administration of growth hormone to underweight patients with chronic obstructive pulmonary disease. A prospective, randomized, controlled study. Am J Respir Crit Care Med 1997; 156: 1800-1806.

40. van den Berghe G, Wouters P, Weekers F, et al. Intensive insulin therapy in the critically ill patients. $N$ Engl J Med 2001; 345: 1359-1367.

41. Puhan MA, Scharplatz M, Troosters T, et al. Respiratory rehabilitation after acute exacerbation of COPD may reduce risk for readmission and mortality -a systematic review. Respir Res 2005; 6: 54-65. 